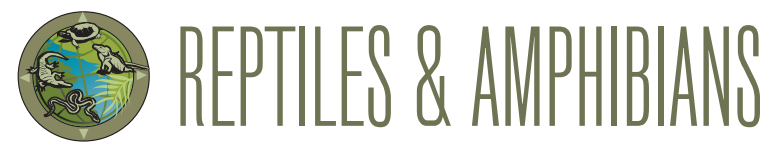

\title{
Mortality of an Eastern Fence Lizard, Sceloporus undulatus (Squamata: Phrynosomatidae)
}

\author{
Jason A. Fantuzzi ${ }^{1}$ and John F. Bunnell ${ }^{2}$ \\ ${ }^{1}$ EcolSciences, Inc., 75 Fleetwood Ave., Rockaway, New Jersey 07866, USA (JFantuzzi@ecolsciences.com) \\ ${ }^{2}$ New Jersey Pinelands Commission, New Lisbon, New Jersey 08068, USA
}

$\mathrm{H}$ erpetofauna often are attracted to anthropogenic refugia because they provide shelter and are suitable for thermoregulation and oviposition (Shine and Bonnett 2009). However, detrimental effects of various forms of "artificial cover" have gone largely unrecognized (see, however, GaticaColima et al. 2016). Herein we describe one potential hazard to squamates known to inhabit disused railways. At $1131 \mathrm{~h}$ on 25 June 2016, we discovered a dead adult female Eastern Fence Lizard (Sceloporus undulatus) (ca. $7 \mathrm{~cm} \mathrm{SVL}$ ) trapped in a discarded railroad tie (Fig. 1) in Cumberland County, New Jersey (GPS locus withheld due to habitat sensitivity). The female was gravid as determined by the presence of four welldeveloped eggs visible through the decomposing body cavity. The lizard, with an autotomized tail, was wedged tightly in a space created by the degradation of the wooden tie. Based on the state of decomposition, we considered the lizard to have been dead for three to five days.

We have observed Scarlet Snakes (Cemophora coccinea), which are known predators of lizards (Palmer and Braswell
1995), inhabiting the same railroad ties with fence lizards, possibly as an extension of underlying subterranean burrow systems. Because we did not witness the entrapment of this lizard, we were unable to determine the cause of its death. However, we suggest that a likely scenario involved a snake pursuing the lizard through the spaces in the railroad tie until it become wedged into a crack in its efforts to escape. Presumably, the snake came away with only the tail of the lizard. We hope that this observation will serve as encouragement to remove human debris in wild habitats, particularly in existing protected areas.

\section{Literature Cited}

Palmer, W.M. and A.L. Braswell. 1995. Reptiles of North Carolina. The University of North Carolina Press, Chapel Hill, North Carolina. USA.

Gatica-Colima, A., A. Robles-Hernandez, A. Rivera-Hernandez, and A. TorresDuran. 2016. Phrynosoma cornutum (Texas Horned Lizard). Mortality. Herpetological Review 47: 301.

Shine, R. and X. Bonnett. 2009. Reproductive biology, population viability, and options for field management, pp. 172-200. In: S.J. Mullin and R.A. Seigel (eds.), Snakes. Ecology and Conservation. Cornell University Press, Ithaca, New York, USA.
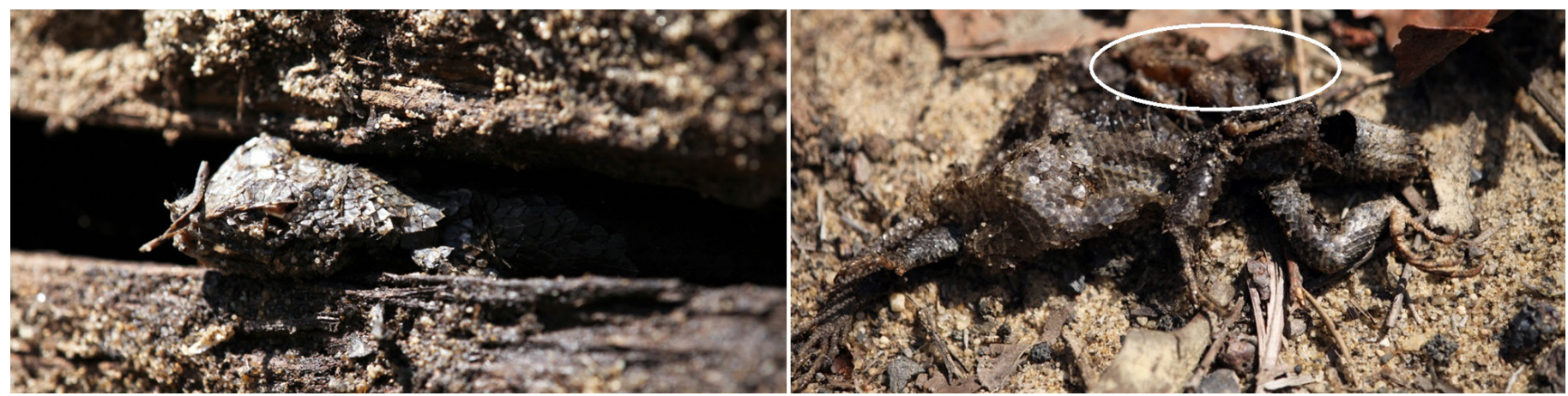

Fig. 1. A dead adult female Eastern Fence Lizard (Sceloporus undulatus) trapped in a railroad tie in Cumberland County, New Jersey, USA (left), and the decomposing carcass with four well-developed eggs (right). Photographs by Michael Bisignano. 